\title{
A Fractional Power Disk Shaped Motor with Superconducting Armature
}

\author{
Gonçalo F. Luís ${ }^{1}$, David Inácio ${ }^{2}$, João Murta Pina ${ }^{2}$, and Mário Ventim Neves ${ }^{2}$ \\ ${ }^{1}$ Faculdade de Ciências e Tecnologia, Universidade Nova de Lisboa \\ Monte de Caparica, 2829-516 Caparica, Portugal \\ ${ }^{2}$ Centre of Technology and Systems, \\ Faculdade de Ciências e Tecnologia, Universidade Nova de Lisboa \\ Monte de Caparica, 2829-516 Caparica, Portugal \\ gfl19047@fct.unl.pt, ddi@fct.unl.pt, jmmp@fct.unl.pt, \\ ventim@uninova.pt
}

\begin{abstract}
A disk-shaped, double stator, induction motor with High Temperature Superconducting (HTS) field coils is proposed in this paper. Copper, typically used in windings of classic machines, limits current density allowed in field coils due to Joule effect losses. Also iron, which is used in magnetic circuits, limits the magnetic flux density obtained in the air gap due to saturation. The application of HTS field coils and iron removal effect in fractional power disk shaped or axial flux motors is analyzed by comparison of two different stator topologies. Twelve HTS field coils made of $\mathrm{Bi}-2223\left(\mathrm{Bi}_{2} \mathrm{Sr}_{2} \mathrm{Ca}_{2} \mathrm{Cu}_{3} \mathrm{O}_{1} 0\right)$ first generation tape, wrapped around a racetrack-shaped nylon core, are assembled. A simple topology was chosen, consisting of six filed coils per semi-stator arranged in the same plane with $60^{\circ}$ displacement. This topology is analyzed theoretically, based on a linear induction motor approach and simulated using a commercial finite elements program, based on the same approach. In order to study the effect of magnetic saturation two stators were built. In the first, the field coils are assembled in steel plates. In the second, the same coils are assembled on nylon plates. The rotor is composed of an aluminum disk assembled on a stainless steel shaft. The HTS coils were cooled by liquid nitrogen $(77 \mathrm{~K})$. Simulations, experimental and theoretical results are consistent, showing high space harmonic distortion for the chosen topologies. It is shown that for this type of low power motors operating at this temperature, as iron saturation is not achieved, ferromagnetic materials removal is not a good option. Besides, flux leakage is to high, degrading developed torque.
\end{abstract}

Keywords: Superconducting tape, armature, induction, disk-shaped, ironless, space-harmonics.

\section{Introduction}

Due to High Temperature Superconducting (HTS) materials ability to carry high current densities with minimum losses when compared to conventional conductors, it is possible to design more compact and lightweight electric motors. 
One of the advantages of superconducting conductors is their capability to create high intensity magnetic induction fields. Nevertheless, if ferromagnetic materials are used, due to saturation, flux density is limited to less than 2 T. In [1] - [3], some studies in the field of ironless HTS motors are performed. The goal of the work presented in this paper is to further study the application of air core HTS motors.

HTS tapes mechanical limitations, turns motors' constructions more complex than conventional motors. In [4] - [10] several topologies of HTS motors are presented.

However a direct comparison between iron and ironless cored motors is never accomplished. In this paper, a simple design is proposed, in order to create two identical HTS motors prototypes and compare the effects of removing ferromagnetic materials.

\section{Contribution to Technological Innovation}

One the main issues in electrical generator and motors is the high power losses due to the high resistivity of the conductors. In order to reduce power consumptions and create a sustainable power usage, more efficient electrical machines are necessary. The ability of HTS machines to work with minimum power losses make them a good substitution for conventional ones.

Other potential advantage in HTS motors is the possibility of iron removal, as mentioned, thus making lighter and compact machines.

These devices may also find potential application in naturally cryogenic environments, as is the case of double-shaded craters near Moon's magnetic poles, where temperatures are typically bellow $50 \mathrm{~K}$. Thus, there is a current need to research and develop this kind of devices, where classical techniques do not always apply.

\section{Motors' Design}

Two prototypes motors are projected; one using a toothless ferromagnetic circuit, referred to as topology T1; and another, referred as T2, which is a ironless version of the first.

Both are disk shaped (or axial flux), double stator, two poles, induction motors. Twelve 20 turns identical HTS, racetrack shaped, field coils, are used, in order to create the travelling filed. These coils are made of $\mathrm{Bi}-2223$ first generation tape. The coils were made considering the mechanical limitations of the tapes. The length of BSSCO tape for each coil is about $7 \mathrm{~m}$. The field coils were tested at $77 \mathrm{~K}$ showing an average critical current of $88 \mathrm{~A}$.

The prototypes design was limited by the coils dimensions and shape. The rotor consists on an aluminum disk assembled on a stainless steel shaft. The rotor thickness was optimized using the goodness factor of the machine. Based on the correction factors referred in [11], the expression of topology T1 goodness factor is obtained

$$
Q(e)=\frac{\pi^{2} f \mu_{0} \sigma_{A l} \tau_{p} c_{b o b} K_{S}}{2 p} \cdot \frac{e}{g_{0}(e) k_{1}(e) k_{s k}(e)\left(1+k_{p}(e)\right)}
$$


where $f$ is the frequency, $c_{b o b}$ the length of one coil, $p$ the number of pairs of poles, $g_{0}$ the airgap, $\tau_{p}$ the pole pitch, $K_{S}$ the Russel-Norsworthy correction-factor due to rotor's overhang, $k_{1}$ the large airgap's correction factor, $k_{s k}$ the correction factor due to the skin effect in finite thickness rotor plates and $k_{p}$ the correction factor due to saturation of armature plates iron. See [11] for correction factors $k_{1}, k_{s k}$ and $k_{p}$ and [12] for $K_{S}$.

The goodness factor evolution as a function of the rotor thickness, for a frequency of $50 \mathrm{~Hz}$, is shown in Fig. 1. Four curves are shown representing different slips of $60 \%, 70 \%, 89 \%$ and $90 \%$. From that figure it can be conclude that the rotor thickness that optimizes the goodness factor is in the range of 3 to $3,5 \mathrm{~mm}$.

A key project's goal was to ensure the dimensions similarity of both prototypes to ensure a reasonable comparison. T1 motor's final design is shown in Fig. 2. The prototype $\mathrm{T} 2$ is identical to $\mathrm{T} 1$, except that the plates are built of nylon instead of magnetic steel.

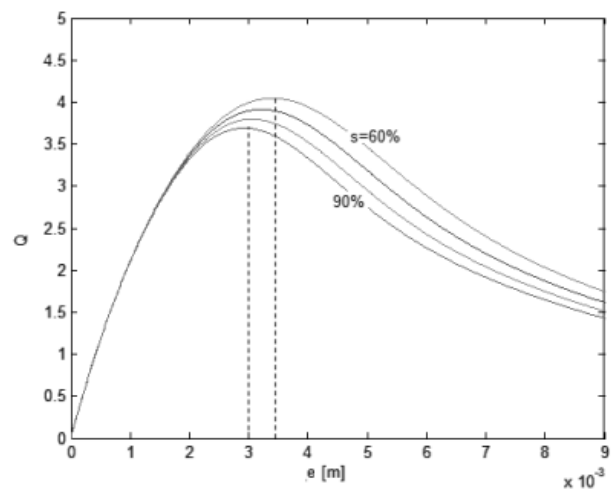

Fig. 1. Goodness factor as a function of rotor thickness, for different slips
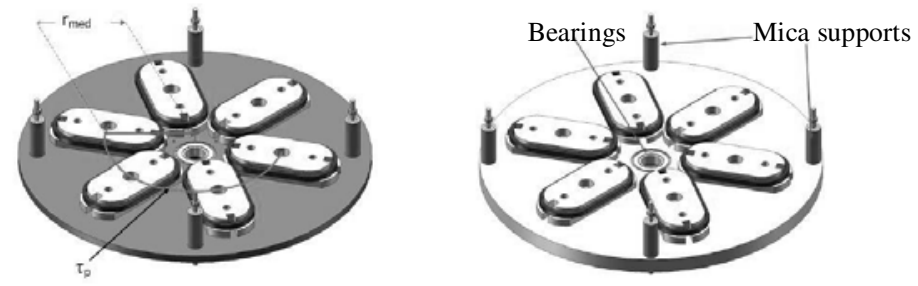

Fig. 2. Final aspect of T1 (left) and T2 (right) semi-stators design

\section{Theoretical Analysis}

In order to predict and analyze motors' operation, a theoretical study is performed. The main objectives are to observe the induction field created by the HTS coils and to predict the torque developed by the rotor. Only the prototype containing ferromagnetic circuits was studied, due to its simplicity. 


\subsection{Travelling Field}

Based on Fourier analysis, the approximate expression of the travelling field, created by the armature, was calculated, showing great harmonic distortion. Fig. 3 shows the armature harmonics. From this figure it is possible to conclude that high order harmonics are not negligible. Thus, calculation of the developed torque is carried out considering the winding harmonics.

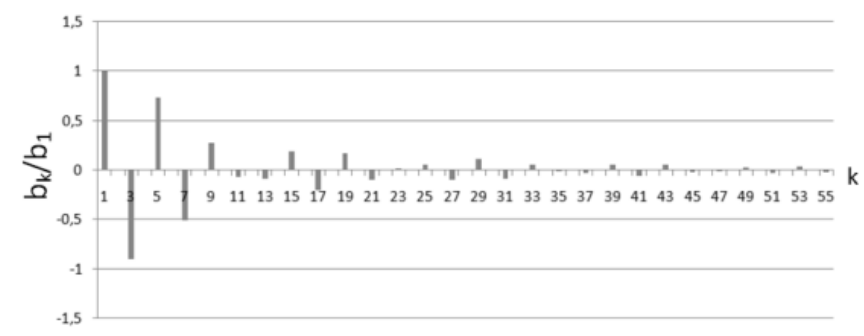

Fig. 3. Spectrum of winding harmonics, normalized by the fundamental's amplitude

\subsection{Developed Torque}

In order to determine the torque developed by the motor, considering the winding harmonics, the individual effect of each harmonic is calculated, and the total torque is the sum of each effect.

Based on [13], the expression of the torque developed by each component, $T_{k}$, is calculated as

$$
T_{k}(\Omega)=r_{\text {med }} \pi J_{1}^{2} b_{k} \cdot \frac{k \cdot \frac{e}{\rho_{v o l}} \cdot\left(\omega_{1}-\Omega k\right)}{\left(\frac{g}{\mu_{0}} \cdot k^{2}\right)^{2}+\left(\frac{e}{\rho_{A l}} \cdot\left(\omega_{1}-\Omega k\right)\right)^{2}},
$$

where the rotor has a radius $r_{m e d}$, thickness $e$ and $\rho_{v o l}$ is the volumetric resistivity of the aluminum. Also, $J_{1}$ is the current density in the HTS coils, $b_{\mathrm{k}}$ is the Fourier coefficient of the $k-t h$ harmonic, $\omega_{1}$ is the travelling field angular speed and $\Omega$ is the rotor's mechanical speed.

The individual components of the resultant torque are represented in Fig. 4.a), where it can be seen the effect of each harmonic $k$. The greater the value of the harmonic the greater the equivalent number of poles, therefore the smaller the equivalent synchronous speed.

Therefore the total developed torque is given by

$$
T_{T}=\sum_{k=1}^{\infty} T_{K}(\Omega) .
$$


The evolution of torque $T_{T}$ as a function of rotor's speed is plotted in Fig. 4.b), and it consists on the sum of the components shown in Fig. 4.a). It is clear that the function tends to a final speed of one third of the synchronous speed of a two pole motor, 3000 $\mathrm{rpm}$. These values represent a slip of $s=0,667$, considering no load operation. For a rotor's speed between 1000 and $2200 \mathrm{rpm}$, the motor behaves as a brake.

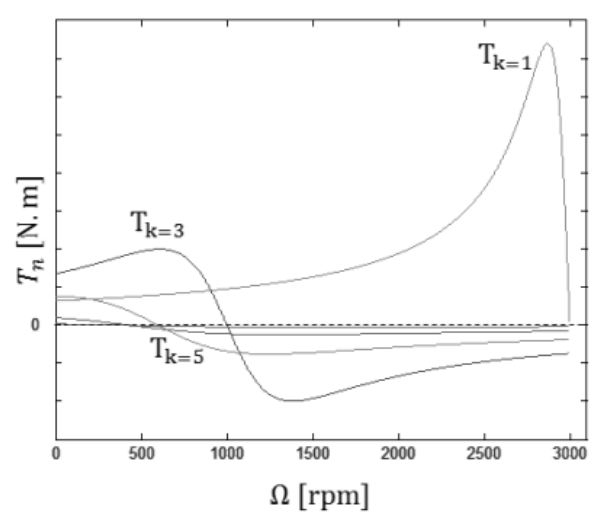

a)

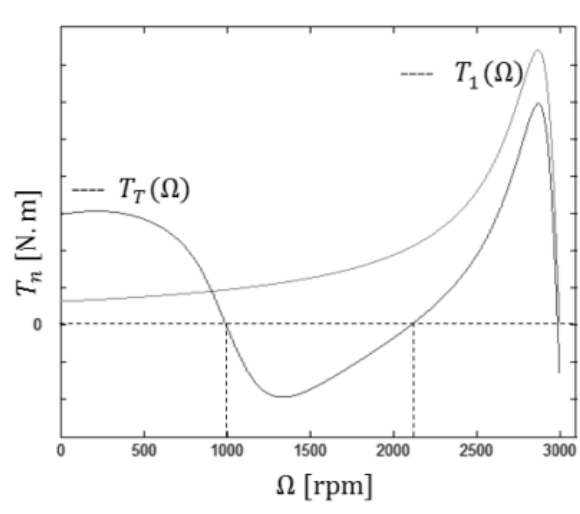

b)

Fig. 4. a) Individual contribution of the main harmonics to the resulting torque. b) Resulting torque as a function of speed.

\section{Simulations}

Simulations were performed with three main goals. The first is to ensure the operation of the prototypes before building them. The second is to verify the theoretical results. The last is to study the effects of an ironless magnetic circuit and compare it whit iron cored topologies.

The simulations were carried out using finite elements commercial software Flux2D, from Cedrat Company. Due to 2D geometry, a linearized versionof the disk motor is studied. An electric current of 60 A per phase is used in simulations.

The T1 prototype is simulated and it is possible to verify the motor's operation. In order to verify the theoretical results, the torque/speed characteristic, $T_{T 1}(\Omega)$, is obtained using imposed speed testes. Fig. 5 (T1) shows the obtained characteristic.

Comparing Fig. 5 (T1) and Fig. 4.b) it is possible to observe the similarities. In both graphics, the rotor's speed tends to a much lower value than the synchronous speed. Therefore, theoretical results correctly demonstrate the degradation of developed torque by winding harmonics.

Two other topologies were simulated. Topology T2, the ironless version of T1 and topology $\mathrm{T} 3$, which consists in adding more iron to the magnetic circuit. Fig. 5 presents torque/speed characteristic of the three topologies. It is possible to conclude that there is no advantage in removing the ferromagnetic circuits, besides devices' 
weight reduction, since the torque decreases. Besides, since flux density only reaches $0.04 \mathrm{~T}$ in the airgap, it is possible to conclude that the magnetic field generated by the coils, is not enough to reach iron saturation, reinforcing previously conclusion.

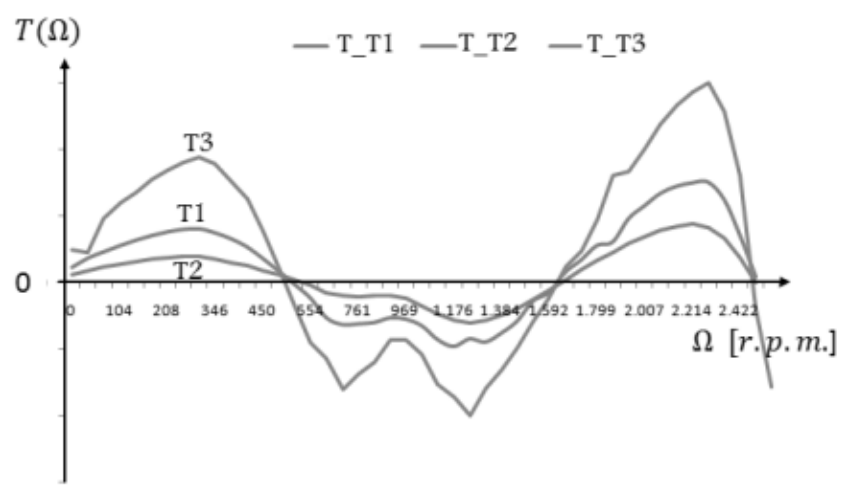

Fig. 5. Simulation results. Comparison of $\mathrm{T} 1, \mathrm{~T} 2$ and $\mathrm{T} 3$ torque/rotor speed characteristics.

\section{Experimental Results}

The prototypes $\mathrm{T} 1$ and $\mathrm{T} 2$ were built accordingly with their designs, see Fig. 6. Both motors were tested at $77 \mathrm{~K}$, with a $5 \mathrm{~V}$ power supply, with $63 \mathrm{~A}$ rms current supplying HTS coils. In order to obtain the torque/speed characteristic, the motors were coupled to a powder brake and several operation points were obtained. These are plotted in Fig. 7 for topology T1. For topology T2, the developed torque was neither enough to overcome nor static, nor dynamic friction. Therefore, no rotor movement is possible.

From these results, it is confirmed that there is no advantage in removing iron materials from the magnetic circuits, at least for this level of power. It is also possible to conclude that, as predicted in theoretical and simulations studies, the windings distribution on the stator results in a large slip.

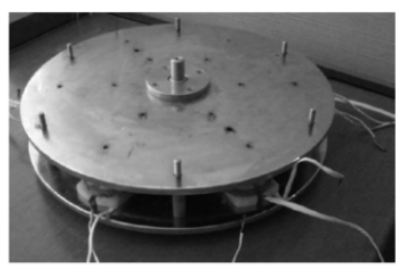

a)

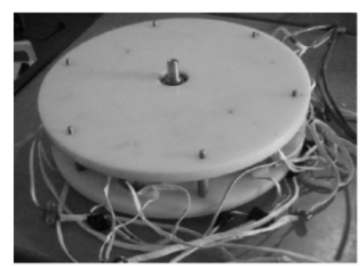

b)

Fig. 6. Final look of the built prototypes: a) Topology T1. b) Topology T2. 


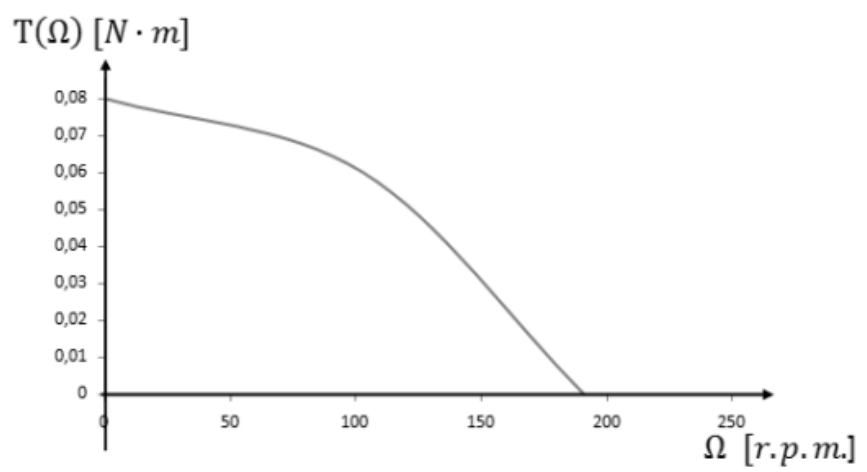

Fig. 7. Experimental torque/speed characteristic for topology T1

\section{Conclusions}

Two axial flux induction motor topologies were presented in this paper, both with HTS armature. Theoretical analysis, simulations and experimental measurements were performed, showing two main conclusions: firstly, there is no advantage in removing ferromagnetic circuits in this type of fractional power HTS motors, since the magnetic field created by the HTS tapes is not enough to compensate for the increased reluctance. Secondly, due to materials' physical restrictions, it was demonstrated that the windings distribution chosen, although simple, introduces high harmonic distortion resulting in poor motor performance. The HTS first generation tapes show great mechanical limitations, hindering the construction of more efficient motors. Also, a new approach for analytic study of the developed torque, for high winding harmonics motors, is presented. It shows results consistent with simulations and experimental results.

\section{References}

1. Masson, P.J., Luongo, C.A.: High Power Density Superconducting Motor for All-Electric Aircraft Propulsion. IEEE Trans. Appl. Supercond. 15(2) (2005)

2. Kwon, Y.K., Baik, S.K., Lee, E.Y., Lee, J.D., Kim, J.M., Kim, Y.C., Moon, T.S., Park, H.J., Kwon, W.S., Hong, J.P., Jo, Y.S., Ryu, K.S.: Status of HTS Motor Development for Industrial Applications at KERI \& DOOSAN. IEEE Trans. Appl. Supercond. 17(2) (2007)

3. Granados, X., Pallares, J., Sena, S., Blanco, J.A., Lopez, J., Bosch, R., Obradors, X.: Ironless armature for high speed HTS disk shaped rotor in self levitating configuration. Physica C 372-376, 1520-1523 (2002)

4. Kovalev, L.K., Ilushin, K.V., Koneev, S.M., Kovalev, K.L., Penkin, V.T., Poltavets, V.N., Gawalek, W., Habisreuther, T., Oswald, B., Best, K.-J.: Hysteresis and Reluctance Electric Machines with Bulk HTS Rotor Elements. IEEE Trans. Appl. Supercond. 2(9), 1261-1264 (1999)

5. Nagaya, K., Suzuki, T., Takahashi, N., Kobayashi, H.: Permanent Magnet Pulse Motor With High- Temperature Superconducting Levitation. IEEE Trans. Appl. Supercond. 11(4), 4109-4115 (2001) 
6. Hull, J.R., SenGupta, S., Gaines, J.R.: Trapped-Flux Internal- Dipole Superconducting Motor\&Generator. IEEE Trans. Appl. Supercond. 9(2), 1229-1232 (1999)

7. Dombrovski, V., Driscoll, D., Shoykhet, B.A., Umans, S.D., Zevchek, J.K.: Design and Testing of a 1000-hp High-Temperature Superconducting Motor. IEEE Trans. Energy Conversion 20(3) (2005)

8. Masataka, I., Akira, T., Masayuki, K., Yoshiji, H., Toshihiro, S., Yoshihiro, I., Takashi, S., Yutaka, Y., Teruo, I., Yuu, S.: Development of a $15 \mathrm{~kW}$ Motor with a Fixed YBCO Superconducting Field Winding. IEEE Trans. Appl. Supercond. (17), 1607-1610 (2007)

9. Schiferl, R., Flory, A., Livoti, W.C., Umans, S.D.: High Temperature Superconducting Synchronous Motors: Economic Issues for Industrial Application. In: PCIC 2006 Conference. IEEE, Los Alamitos (2006)

10. Pina, J.M., Neves, M.V., McCulloch, M.D., Rodrigues, A.L.: Design of a linear synchronous motor with high temperature superconductor materials in the armature and in the field excitation system. Journal of Physics: Conference Series 43, 804 (2006)

11. Boldea, I., Nasar, S.A.: Linear Motion Electromagnetic devices. Taylor \& Francis, Abington (2001)

12. Rodrigues, A.L.: Design of Low Speed Linear induction Motor. M.Sc. thesis in Power Systems and Electrical Machines, Imperial College of Science and Technology (1973)

13. Yamamura, S.: Theory Of Linear Induction Motors, 2nd edn. University of Tokyo Press (1978) 